\title{
Some Technical Aspects for Sustainable Biodiesel Production
}

\author{
Imam Paryanto, Agus Kismanto, Khairil Amri, Maharani Dewi Solikhah \\ Balai Rekayasa Disain dan Sistem Teknologi - Badan Pengkajian dan Penerapan Teknologi \\ Gedung 480 PUSPIPTEK Serpong Tangerang Selatan 15314 Banten Indonesia \\ E-mail: imam.paryanto@bpt.go.id
}

\begin{abstract}
According to Brundtland Commission (1987), sustainability means the ability to meet the needs of the present without compromising the ability of future generations' abilities to meet their own needs. The term of sustainability has multi-dimensional objectives of social, environmental and economic. Without ignoring the importance of social, environmental, and economical aspects of sustainability, this study will only highlight some technical aspects for sustainable biodiesel production and, of course, the final goal will target the implication of improved social, environmental and economical conditions. Some technical aspects for sustainable biodiesel production cover the multi-discipline activities at the design stage and at the operation stage of biodiesel production plant. The design stage can be divided into conceptual design, basic engineering design and detailed engineering design. At this stage, the design parameters should consider the selection of the type and availability of raw material, biodiesel plant capacity and location, the efficient production process, the availability of utilities and supporting infrastructures, waste (environmental) treatment, and raw material and product handling facilities. And during the operation of biodiesel plant, some important technical issues are the production process activities according to the Standard Operating Procedure (SOP), awareness of safety and Hazard and Operability Study (HAZOP), scheduled maintenance activity, waste management, product quality control, and further, if possible, efficiency improvement in the production line through $R \& D$ activities and technological advances.
\end{abstract}

Keywords — Biodiesel; Sustainability; Sustainable Biodiesel Production.

\section{INTRODUCTION}

Biodiesel is a renewable diesel fuel produced by methanolysis of vegetable oils or lipids with or without presence of a catalyst. In biodiesel production, one mole of triglyceride reacts with three moles of alcohol (molar ratio of methanol to vegetable oil of 3:1) to form one mole of glycerol and three moles of the respective fatty acid alkyl esters [1]. The most common method of commercial biodiesel production is trans-esterification of oil (triglycerides) with alcohol (methanol) in the presence of a catalyst which gives biodiesel (or fatty acid methyl esters FAME) as a product and glycerol as a by-product. The selection of catalyst depends on the amount of free fatty acid (FFA) present in the raw material oil. For triglyceride feedstock with lower amount of FFAs, alkaline-catalyzed trans-esterification reaction can gives better conversion in relatively short time while for higher FFAs containing oil feedstock, acid-catalyzed esterification reaction followed by alkaline-catalyzed trans-esterification reaction is used [2], [3].

Biodiesel has become a new alternative fuel for the future fuel demands because its abundant raw material sources, renewable and low environmental effects. Biodiesel fuel has similar properties to that of diesel fuel produced from crude oil and can be used directly for existing diesel engines or as a mixture with petro-diesel fuel. Commercially, biodiesel blends are called as B5, B10, B20 or B100 to represent the volume percentage of biodiesel component in the blend with petro diesel as 5, 10, 20 and 100\%, respectively. Currently, many countries around the world have explored commercially biodiesel blends for their vehicles.

Biodiesel has offered the prospect of increased market competition and oil price moderation. A healthy supply of this bio-fuel can help to reduce the dependency on fossil fuels, especially in the transport sector. Biodiesel as one of bio-fuels can offer the prospect of sustainability in price, environment and economics. However, biodiesel currently being utilized has been criticized for their adverse impacts on the natural environment, food security and land use [4]. The challenge is to support biodiesel development and utilization to ensure that biodiesel commercialization is sustainable.

There are many important aspects related with the biodiesel production activities, such as social aspects, economical aspects, environmental aspects and technical aspects. From the technical aspects, the choice of technology for processing of raw material to biodiesel has to consider 
the kind of raw materials, products, material handling, material and heat balances management, general arrangement, equipment, pump and instrumentation and control management in order to guarantee the efficiency and sustainability of process.

According to Brundtland Commission (1987), sustainability means the ability to meet the needs of the present without compromising the ability of future generations' abilities to meet their own needs [5]. The term of sustainability has multi-dimensional objectives of social, environmental and economic. Without ignoring the importance of social, environmental, and economical aspects of sustainability, this study will only highlight some technical aspects for sustainable biodiesel production and, of course, the final goal will target the implication of improved social, environmental and economical conditions. It will cover the multi-discipline activities starting from the engineering design stage to the operation of biodiesel plant.

\section{DESIGN Phases Of Biodiesel Plant}

\section{A. Design And Engineering of Biodiesel Plant}

Design is a creative activity, and as such can be one of the most rewarding and satisfying activities undertaken by an engineer. It is the synthesis, the putting together, of ideas to achieve a desired purpose. The designer starts with a specific objective in mind, a need, and by developing and evaluating possible designs, arrives at what he considers the best way of achieving that objectives [6].

The design stage of a biodiesel plant can be divided into the conceptual design, basic engineering design, and detailed engineering design [Figure 1]. At the stage of conceptual design phase, the objective and specification of the biodiesel plant design need to be defined, such as biodiesel production capacity, specification of raw material, biodiesel plant location, production process technology and types of utilities to be used. It is then followed by construction of process flow diagram (PFD) and calculation of mass and heat balances. The safety design factors are considered in the calculation of mass and heat balances. The next stage of the design (i.e. basic engineering design) is to draw a piping and instrumentation diagram (P\&ID) which shows the engineering details the equipment, instruments, piping, valves and fittings, and their arrangement. The safety and performance considerations in P\&ID are needed for the utilization, selection and sizing of equipment as a unit operation and for the application of appropriate instrumentation and control system. When it comes to the detailed engineering design, the sufficient safety design factors in calculation and selection of all equipment have to be allowed for safe design and operation of sustainable biodiesel plant.

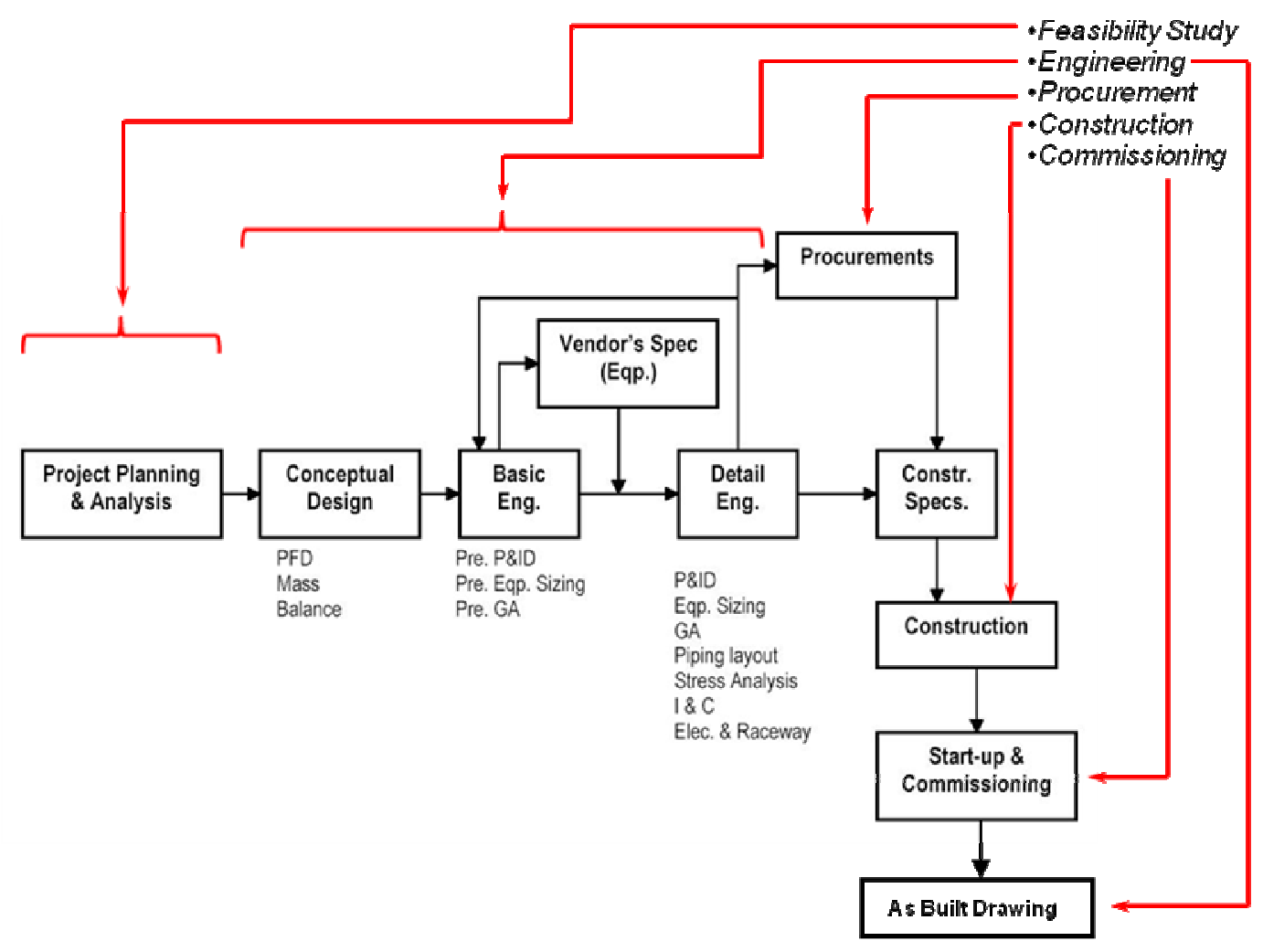

Fig. 1. Design stages of chemical/biodiesel production plant 
The best selected design should include consideration of high yield, minimum loss and less waste. High yield is generated from high reaction conversion, good separation of biodiesel from its impurities, and appropriate recovery process. The biggest source of loss in biodiesel plant comes from methanol having boiling point near to the reaction temperature. The design of methanol vapour trap or condenser and the recycle of excess methanol is an important issue to prevent loss. Waste treatment design could be significant issue for the total fixed capital. Most of waste from biodiesel plant comes from water that used for washing and methanol recovery. Glycerol could become by product instead of waste by additional purification process or could be burned as fuel for boiler since glycerol's caloric value $17.0 \mathrm{MJ} / \mathrm{kg}$ [7].

All production processes are to some extent hazardous, but in chemical processes there are additional, special, hazards associated with the chemicals used and the process conditions. So, the process and plant designers must be aware of these hazards, and ensure, through the application of good engineering practice, that the risks are reduced to acceptable levels. In order to understand the hazard and risk, a hazard and operability study (HAZOP Study) needs to be carried out. A HAZOP Study is a procedure for the systematic, critical, examination of the operability of a process. It indicates the potential hazards that may arise from deviations from the intended design conditions [6].

\section{B. Selection of Raw Material, Location and Utilities for Sustainable Biodiesel Plant}

Major raw materials used to produce biodiesel are vegetable oil, alcohol (methanol) and catalyst. There are several types of vegetable oils available in the market such as palm oil (and its derivatives), Jatropha oil, rapeseed and soybean. The raw material quality, which may be stated with parameters of free fatty acid content, water content and gum content, can determine the process reaction and route to produce biodiesel, and further, determine the price of production cost.

In order to secure the feedstock and reduce the cost for sustainable biodiesel production, it is suggested to supply the feedstock from the local source. The selection of the oil feedstock is one of the important keys for sustainable biodiesel production. One of the potential oil feedstocks for biodiesel production in Indonesia is crude palm oil (CPO) and its derivatives, such as stearin (RBDPS) and palm fatty acid distillate (PFAD). If CPO and off-grade CPO (collected from the waste pond) are used, therefore, to locate biodiesel plant in the area of palm oil mill is more sustainable. In this case, the sources of utilities (water, steam and electricity) for biodiesel plant can be supplied from the palm mill to reduce the investment cost, transportation cost, and operating costs and to ensure the sustainability of the biodiesel plant since palm oil mill uses biomass to produce steam and electricity. Palm oil production through sustainable plantations has been discussed in [8].

Sustainable biodiesel production has to use oil feedstocks which are produced in sustainable manner. There are some categories for sustainable oil feedstocks for biodiesel production [9], as the following :

a. oil feedstocks are produced with the consideration of long-term maintenance and enhancement of soil quality and conservation,

b. production of oil feedstocks must protect water quality and conserve water resources,

c. oil feedstocks for biodiesel have to consider ecosystem protection and biodiversity potential.

d. production of oil feedstocks does not increase GHG emissions ad should increase the sequestration potential of current land use when possible,

e. oil feedstocks production should improve energy and resource conservation,

f. oil feedstocks for biodiesel production can be produced from waste and rendered oils and fats,

g. production of oil feedstocks should consider safe working conditions for workers,

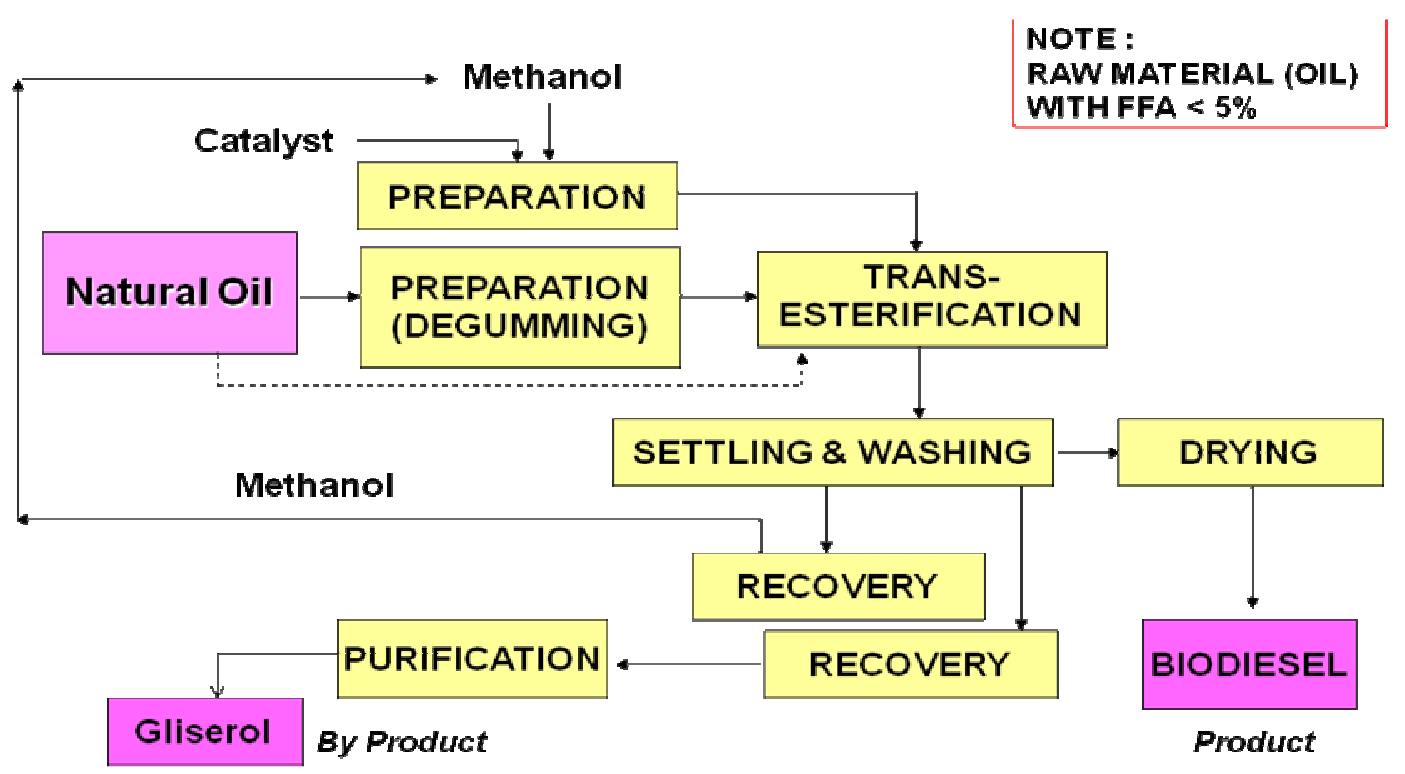

Fig. 2. Biodiesel production process via trans-esterification. 


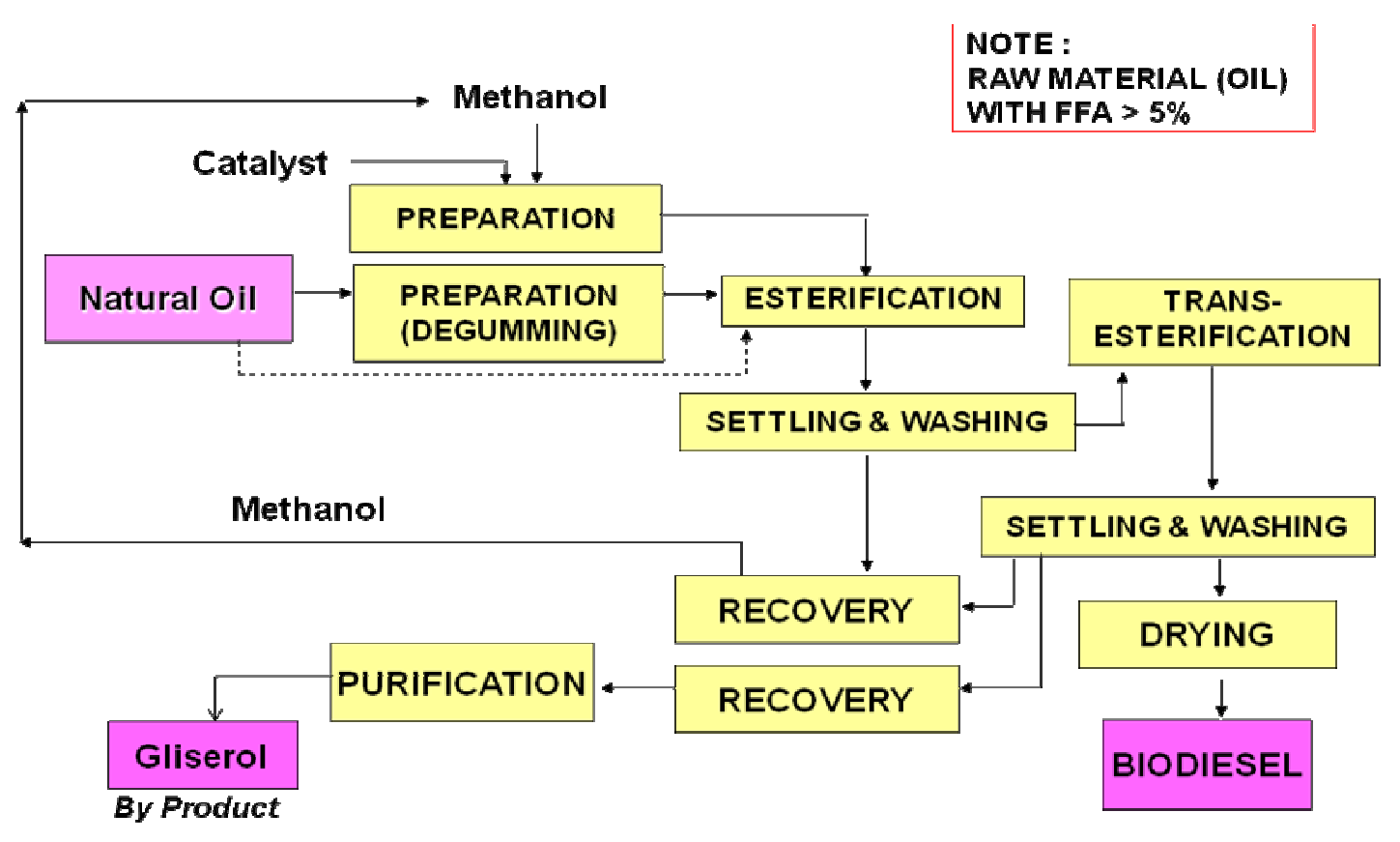

Fig. 3. Biodiesel production process via esterification followed by trans-esterification.

\section{Biodiesel Production Processes}

As previously mentioned that biodiesel production processes were determined by the type of raw material used. The parameter of free fatty acid content is important factor to select either esterification or trans-esterification reaction path. The general biodiesel production method can be described in Figure 2 and Figure 3.

Usually, biodiesel production is started with the treatment of vegetable oil, and preparation of methanol and catalyst. It was then followed by reaction step to convert vegetable oil and methanol to produce biodiesel and glycerol (for the case of transesterification). Biodiesel is then separated from glycerol, and purified (by washing and vacuum evaporation) and filtered. Unreacted methanol is then recovered and reused for the next step of reaction process. This process is relatively simple and with conversion efficiency of more than $95 \%$. However, this path consumes large amount of water for wet washing to remove the salt produced from the neutralization process and the residual acid or base catalyst. MPOB, Lurgi, EsterFIP published and commercialized this technology already [10].

\section{OPERATION OF BIODIESEL PLANT}

In a biodiesel plant, besides main process equipment, supporting facilities are needed such as steam generator (boiler), electricity power source, and water supply facilities. For handling the raw material and product, the biodiesel plant is supported with several storage tanks to supply raw materials and to store the products in a certain period of time. The capacity of this facility is calculated based on the biodiesel production capacity.

Most of the biodiesel production facilities uses methanol mixed with an alkaline/acid catalyst to perform a trans- esterification/esterification reaction. Generally, the higher free fatty acid contain in the vegetable oil required the more volume of methanol used for the reaction. The un-reacted methanol is then recovered by evaporation or distillation process. Methanol is one of the volatile and hazardous materials because of its low boiling point and reactive chemical. Hence, understanding in methanol handling and application will support the safe and sustainable biodiesel production. In order to increase safety and loss prevention during the operation of biodiesel plant, besides the implementation of safety design factors, some considerations have to be applied in the process design and operation as the following:

a. identification and assessment of hazards,

b. control of hazards,

c. limitation of the risk/loss.

Understanding properties and characteristics of raw material and chemicals involved in the biodiesel production process is also necessary for the proper and safe use and handling of biodiesel and other chemicals [11].

To carry out sustainable biodiesel production, there are several technical aspects need to be considered that sustainable biodiesel production has to [9]:

a. follow the Standard Operating Procedure (SOP) for the operators to safely achieve the target of biodiesel production capacity/yield and quality,

b. minimization of waste and emissions (methanol vapour, GHG, particulates, nuisance odours) to reduce the release of pollutants into the air,

c. use of minimum utilities (water, steam and electricity) for efficient consumption and lower biodiesel cost production,

d. awareness of biodiesel plant safety conditions to protect health and safety operators/workers and communities, 
e. regular maintenance of equipments to reduce idle capacity of biodiesel plant,

f. control of biodiesel quality for satisfaction and benefit of biodiesel users,

g. implementation of good material handling and distribution so that lost and risk can be minimized.

\section{CONCLUSIONS}

The activities at the design phase of biodiesel plant are the important starting point to achieve the target of sustainable biodiesel production. The design phase objectives are to determine the optimum design parameters and to produce the best design of biodiesel plant with high yield, minimum loss, and less waste, as well as low investment and production costs. When it is operated, sustainable biodiesel plant can produce the output of good quality of biodiesel, high standards of operational safety, and good control of hazard risk and material handling.

\section{REFERENCES}

[1] G. Knothe, "Some aspects of biodiesel oxidative stability (Review)", Fuel Processing Technology, 88, pp. 669-677, 2007.

[2] U. Schuchardta, R. Serchelia, R.M. Vargas, "Transesterification of vegetable oils : a review”, J. Braz. Chem. Soc, 9, pp. 199-210, 1998.

[3] L.C. Meher, D.V. Sagar, S.N. Naik, "Technical aspects of biodiesel production by transesterification - a review", Renewable and Sustainable Energy Reviews, 10, pp 248-268, 2006.

[4] G. Quaiattini, Biofuels are part of the solution, Canada.com, April 25, 2008.

[5] United Nations Document, "Our Common Future, Chapter 2: Towards Sustainable Development", available online at http://www.un-documents.net/ocf-02.htm\#I

[6] J.M. Coulson and J.F. Richardson, Chemical Engineering, Volume 6, Pergamon, 1989.

[7] A.L. Stephenson, J.S. Dennis, and S.A. Scott, "Improving the sustainability of production od biodiesel from oilseed rape in the UK", J. Process Safety and Environment Protection, 86, pp. 427 440, 2008.

[8] Y. Basiron, "Palm oil production through sustainable plantation", Eur. J. Lipid Sci. Technology, 109, pp 289-295, 2007.

[9] Anonim, "Principles and Baseline Practices for Sustainability", Sustainable Biodiesel Alliance, 2011.

[10] J. Janaun. and N. Ellis, "Perpective on biodiesel as sustainable fuel", J. Renewable and Sustainable Energy Reviews, 14, pp. 1312-1320, 2010 .

[11] Anonim, NREL Biodiesel Handling and Use Guide, US Dept of Energy, 4th Ed., January 2009. 